\title{
PARASITES OF RUMINANTS IN THE JACKSON HOLE AREA: \\ SCARABAEOID BEETLES ACTING ON LUNGWORM, Dictyocaulus hadweni, LARVAE IN ELK AND CATTLE FECES
}

Robert C. Bergstrom

Division of Microbiology and Veterniary Medicine University of Wyoming Laramie

A knowledge of current prevalence and intensity of lungworm infections in elk and domestic ruminants sharing the same range would be useful to wildlife managers, ranchers, forest service personnel and others.

Iimited epidemiological studies of the interaction of hosts and their parasites and the possibilities of cross-transmission from wild to domestic ruminants or from domestic to wild ruminants have been conducted in Georgia (Davidson, et al., 1981) and on a similar scale in some other states but not in Wyoming.

\section{Objectives}

1. A continuation of the study of prevalence of Dictyocaulus sp. lungworm in elk in Teton and Yellowstone National Parks throughout the various seasons of the year.

2. Initiate research of the prevalence of Dictyocaulus sp. in cattle sharing ranges, usually summer ranges, with elk.

3. Analyze genera of nematodes recovered from vegetation taken from the cattle-elk ranges. Isolate Dictyocaulus sp. from the vegetation or from elk and cattle feces.

4. Continue studies of trichostrongylid nematodes in cattle in the areas adjacent to the national parks or forest service land where Dictyocaulosis has been a problem during the past few years.

Spring months are the time of heavy contamination of vegetation by lungworm larvae but spring-like conditions are encountered at higher elevations in the Rocky Mountains where infective larvae of stomach or intestinal worms as well as lungworm larvae may be important potentiators of disease much later in the season than at lower elevations.

\section{Methodology}

Lungworm larvae will be isolated from elk fecal material by a rapid, pellet-washing technique previously developed by the writer at the UW-NPS Research Center. Lungworm larvae will be isolated from cattle feces by the Baermann funnel technique.

Previously (1975-1982) we have not isolated the larvae of Dictyocaulus on 
vegetation within the Teton Park area north of the Jackson Hole Elk Refuge. Larvae have been found around the fecal material of elk along the Gibbon River area in Yellowstone Park. However, in that area, the elk feed within the same general area throughout most of the year. The biotic potential of the lungworm larvae or "infection pressure" along the Gibbon Meadows may be similar to that of the elk refuge during the spring months. However, in two small grass collections, infective larvae have not been found on the refuge vegetation. Such work should be continued. Vegetation from areas on elk-cattle ranges (mainly Forest Service permit areas of Teton-Fremont Counties) should also be checked for the presence of the infective larvae. Vegetation will be "Baermannized" and the parasitic larvae separated from the free-living larvae by adjusting the $\mathrm{pH}$ of the Baermann fluid to 2-2.5.

Previously, we have obtained fecal samples from elk in Yellowstone (Gibbon River area) but a limited number of elk fecal samples should be collected from the Lamar River herd during late May or June.

Fecal samples from cattle in Teton County and adjacent areas will be analyzed by the Baermann technique (isolation of larval forms from vegetation or fecal material) in order to see whether bovids are carrying lungworm at the same or different times of the year than elk. The bovids could be infected and act as carriers of Dictyocaulus and therewith posing problems for the elk and/or the elk may be reservoirs of infection for the bovids.

\section{Previous Work}

From research results gathered during the past 10 years, the present investigators have shown the time of infection and re-infection of elk annually by Dictyocaulus sp. lungworm (Bergstrom, 1975). In general, the data published in 1975 resemble those of Worley and Barrett, (1964) who worked with the Lamar River elk in Yellowstone National Park. The reason for predictable annual infections of elk in the Tetons and in Yellowstone Park herds has not yet been shown.

\section{Results}

Seventy-five per cent of yearling steers on a leasing arrangement on a ranch along the Buffalo Fork River, Teton Co., Wyoming, were pasitive for Dictyocaulus sp. lungworm in August, 1983. During the research effort in May, 1984, another ranch 3 miles northeast of the former ranch was checked via fecal sampling, suctose floatation-centrifugation and by Baermann funnel concentration-collection techniques for first stage larvae in fecal samples from neonatal calves, yearlings and adult, lactating cows. All bovines checked were negative for Dictyocaulus lungworm. Abomasal and intestinal Trichostrongylid egg counts were low in yearlings ranging from 0-160 e.p.g. with a mean of 49 eggs/gram (non-clinical levels). Cows had a mean e.p.g. count of 39.

Mature cow elk, sampled in Teton National Park, mostly south of Signal Mt., May, 1984, showed clinical signs of spring stress. Eighty-five percent of such 
cows were positive for Dictyocaulus sp. lungworms. A smaller number of yearling and mature male elk were also checiked with a relatively high percentage (60-70\%) positive for lungworm in May. Calving was about to start by the 25th of May. Identification of yearling female elk feces was difficult but where a few such fecal samples could be identified from the age-sex group, almost 1008 were positive for Dictyocaulus sp.

Summer research results (August, 1984).

During the third week of August, over 90 fresh fecal samples from mature female elk were collected and checked via the Baermann technique for the presence of first-stage larval forms of Dictyocaulus sp. Some fecal samples had to be discarded because Aphodius spp. beetle larvae or adults were found in the samples. Of 82 samples remaining, 44 percent were positive for lungworm larvae. Five large, mature bull elk were checked on August 25. All were negative for lungworm. Nine calves, nearly three months of age were checked and all found negative for lungworm in feces.

Gibbon River elk.

Cooperative research with Dr. David Worley, Montana State University, Bozeman, and collections of elk feces along the Gibbon R.-Madison R. (especially the Gibbon R. and Elk Park meadows) Yellowstone National Park, was continued with 13 fecals from mature cow elk showing a prevalence of $85 \%$ and from 0.1 to 18 Dictyocaulus larvae per gram of feces in May 1984. August collections along the Gibbon $\mathrm{R}$. were difficult due to rainy weather and a paucity of elk at that time of year. Of the few samples that were collected by Dr. Worley and his students, only about $20 \%$ were positive for lungworm larvae.

Summary and Conclusions: 1984 research results.

1. Data collected from fecal analyses for the presence of parasites of cattle in the Buffalo River Valley, Teton County, Wyoming in May, 1984, indicate very different results than the data of August, 1983 which was gathered from yearling steers on leased grass along the Buffalo River. Not all bovines sharing grazing-browsing with elk become infected with Dictyocaulus lungworms. Probably the yearling steers of 1983 carried lungworm infections to the other bovines on those pastures that summer.

2. Adult female and yearling bovines in the Buffalo River valley were carrying moderate numbers of abomasal and intestinal worms according to worm egg numbers in fecal samples. No clinical cases were found.

3. Even though fewer elk wintered on the National Elk Refuge near Jackson (1983-84), the percentage of cow elk pasitive for lungworms in May, 1984 was high (85\%).

4. Gibbon River elk carried lungworm as in 1983 with percentages of prevalence like those of elk in the same area in 1983 and similar to the per cent prevalence of elk at the same time of year in the Tetons. 


\section{References}

Bergstrom, R. C. 1975. Prevalence of Dictyocaulus viviparus in elk in Teton Co. Wyoming. J. Wildl. Dis. 1l:40-44.

Davidson, W. R., F. A. Hayes, V. F. Nettler, and F. E. Kellogg. 1981. Diseases and parasites of White-Tailed Deer. Misc. Pub. No. 7 Tall timber Res. Sta. Tallahassee, FL 458 pp.

Worley, D. E. and R. D. Barrett. 1963. Studies on the parasites of the Northern Yellowstone elk herds. Prog. Rept. Nat'l. Park Ser., Mammoth, WY. pp. 10-28. 